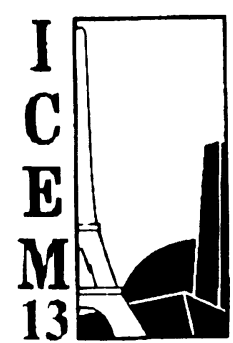

PARIS 1994

\title{
ICEM 13
}

\section{(Paris 94)}

The organization of $13^{\text {th }}$ International Conference on Electron Microscopy is passing through a very busy phase. Since the Seattle Congress, our goal has been to organize a meeting reflecting the most recent evolution of the techniques that are our common tools, in particular electron microscopy, and also signalling the appearance of new or more precise applications in the fields of materials science and biology.

Since the Seattle Congress, however many things have changed. In particular, specialists talk much more in terms of microscopy generally rather than of Electron Microscopy alone. Indeed, in order to solve technical, research or practical problems, we need to increase considerably our use of complementary techniques, which will enable us to analyse the questions more thoroughly. The central purpose of ICEM-13 is therefore to give people working with complementary techniques the opportunity of meeting together in Paris to discuss problems of common interest. People confronted with current industrial or research problems will be able to learn directly from the practitioners of these various approaches the most recent advances in theses techniques, namely, electron, ion, light and near-field microscopy. The Congress will thus allow a comparison to be made of the information gained from the most recent developments. Often the new techniques (new electron guns, holography, low energy microscopy ...) and the recent developments and applications enable us to improve our knowledge and understanding of old problems concerning materials or biological samples or provide insight into the properties of new materials, surfaces and non-conducting materials. The ability to explore materials at very high resolution, to detect atoms or atomic columns, to determine with precision the symmetry of a crystal or to observe lattice defects, to determine the elemental composition or the electronic structure is clearly fascinating. We know the importance of being able to compare analyses of the same samples in bulk form and in thin foils, and to compare the results of analyses performed by means of different techniques. For instance, the impressive progress

made in cryo-EM techniques together with the SEM techniques, is extremely important. Moreover, the role that the new areas of microscopy play or that we suggest they could play in biology, for the localization of molecules or for establishing the structure of macromolecular systems, is also exciting. We appreciate, although often with difficulty, the importance of determining the relation between microstructures and macroproperties.

The scientific programme should therefore satisfy the needs of the participants in their exploration of the most recent advances in the different fields, which are considered separately. At the same time, we shall attempt to take into account the wish of many users to be offered a comparison of complementary techniques and applications. As far as possible, communications between people from different scientific horizons will be facilitated. The themes of the specialist symposia for both materials scientists and biologists and also those of common interest to these two groups have already been defined. On the other hand, the themes of the poster sessions are not yet completely finalized: their exact planning will depend on the overall responise of the participants. The general topics have been defined with the help of all the member societies of IFSEM. The International Scientific 
sory Committee was selected from the many proposals submitted at our request by the societies and members of the IFSEM executive committee.

The Congress will comprise:

- Common Symposia of common interest to physicists and biologists in plenary sessions.

- Symposia which are more specialized. Their goal is often to strike the balance between different approaches for a given kind of problem. These symposia are structured as follows:

a) Interdisciplinary developments and tools

b) Applications in materials science

c) Applications in life sciences

These symposia will be composed of invited talks, but also of oral presentations selected from the papers proposed by participants in response to the third circular, which will be sent in Autumn'93. The other papers will be presented as posters.

- Poster sessions on even more specialized subjects. These poster sessions will be composed of two parts :

a) One in the poster-hall, where authors will be expected to be ready to discuss and answer questions about their posters.

b) The other in a lecture theatre will be under the responsability of two chairmen who will present a synthesis of the theme and encourage vigorous discussion between participants and contributors to the session.

All the posters will be exhibited during a substantial part of the Congress.

- Open labs. These permanent structures will be organized under the responsibility of researchers with the participation of companies. Two open labs have been chosen:

- Computers in microscopy

- Techniques of specimen preparation

For computers we are interested by your needs. Which type of computer or system do you use (Vax, PC, MacIntosh, Unix system, HP, Sun, Silicon Graphics...)? Which memory do you need (disks, Bernoulli), which interfaces... and what kind of compilers?

If you are interested in these particular subjects, please contact:

- For computers: P. Trebbia (Fax: (33) 260532 50),

- For specimen preparation: $\quad$ O. Perche (Fax: (33) 146708846 ) in biology and

P. Chemelle (Fax: (33) 1308737 01) in physics.

- Workshops, which will be organized a few months only before the Congress. Their object is to discuss topics in rapid developments. If you want to propose a theme do not hesitate to contact us.

- Scientific equipment exhibition. The long-established tradition of organizing such an event has been preserved and we are pleased that companies have already reserved space for participating in the Congress. This participation is obviously indispensable to the success of the Congress. We hope that the commercial organizations will also participate fully also in the open labs.

A separate area has been set aside for scientific publications (books and journals).

- Exhibition of user companies. In addition to companies manufacturing instruments, attachments, softwares or other products, we have asked user companies and scientific institutions to contribute to the Congress and more specifically to the exhibition. In this way these companies can 
establish direct contact with the international community of microscopists and find, for instance, the right people to assist with the problems they have encountered.

In spite of the rather difficult international economic situation, we are convinced that this Congress will be a success. The response we have already received allows us to be optimistic. More than one year before the meeting, the number of preregistrations received is over 1500 from about 45 different countries.

PROGRAMME OF SYMPOSIA

COMMON SYMPOSIA

CryoEM techniques for macromolecular systems

Advanced SEM techniques

Which microscopies in the year 2000 ?

\title{
SYMPOSIA
}

\section{- INTERDISCIPLINARY DEVELOPMENTS AND TOOLS}

\section{Imaging}

Optics and detection of charged particles

Holography

Quantitative high-resolution electron microscopy

Near-field microscopy

Image analysis, processing and modelling

$3 \mathrm{D}$ reconstruction and tomography

\author{
Analysis \\ Analytical microscopy at high spatial resolution \\ Analysis of bulk specimens \\ Optical microspectroscopies

\section{Diffraction} \\ Convergent-beam electron diffraction \\ Electron diffraction and crystallography
}

\section{- APPLICATIONS IN MATERIALS SCIENCE}

Defects and deformation microstructure

Interface structures

Clusters, nanoparticles, fullerenes and related structures

Phase transformations

Structure and microstructure of solids

Surfaces: structures and reactivity

Beam injection techniques

\section{- APPLICATIONS IN LIFE SCIENCE}

Cell polarity and cell motility

Cell dynamics 
Cell interactions and extracellular matrix

Ultrastructural localization of molecules

Nucleus, chromatin and chromosome mapping

Macromolecular assemblies

High-resolution imaging and electron crystallography of biomacromolecules

Cryotechniques: static and dynamic approaches

Pathology and diagnosis

New microscopy in biology

Analytical microscopies

Biomaterials

\section{Using microscopes? \\ Come to ICEM-13}

17-22 July 1994, Palais des Congrès de Paris

I would like to thank all the people who help us in the organization of this Congress. It would be too long to give the list here. However, I would like to thank here President Elmar Zeitler and General Secretary Arvid Maunsbach for their help in this difficult task, and also the presidents of the societies members of IFSEM.

B. JOUFFREY

President of ICEM 13

June 1993 